OPEN ACCESS

Edited by: Luis Puelles,

University of Murcia, Spain

Reviewed by:

Richard S. Nowakowski,

Florida State University College of Medicine, USA

Jean-Pierre Hornung,

University of Lausanne, Switzerland

*Correspondence:

Chiharu Tohyama

tohyamac-tky@umin.org

Received: 21 September 2016 Accepted: 17 January 2017

Published: 07 February 2017

Citation:

Kimura E and Tohyama C (2017) Embryonic and Postnatal Expression of Aryl Hydrocarbon Receptor mRNA in Mouse Brain. Front. Neuroanat. 11:4. doi: 10.3389/fnana.2017.00004

\section{Embryonic and Postnatal Expression of Aryl Hydrocarbon Receptor mRNA in Mouse Brain}

\author{
Eiki Kimura ${ }^{1,2}$ and Chiharu Tohyama ${ }^{1,2 *}$ \\ ${ }^{1}$ Laboratory of Environmental Health Sciences, Center for Disease Biology and Integrative Medicine, Graduate School of \\ Medicine, The University of Tokyo, Tokyo, Japan, ${ }^{2}$ Environmental Biology Laboratory, Faculty of Medicine, University of \\ Tsukuba, Tsukuba, Japan
}

Aryl hydrocarbon receptor (AhR), a member of the basic helix-loop-helix-Per-Arnt-Sim transcription factor family, plays a critical role in the developing nervous system of invertebrates and vertebrates. Dioxin, a ubiquitous environmental pollutant, avidly binds to this receptor, and maternal exposure to dioxin has been shown to impair higher brain functions and dendritic morphogenesis, possibly via an AhR-dependent mechanism. However, there is little information on AhR expression in the developing mammalian brain. To address this issue, the present study analyzed AhR mRNA expression in the brains of embryonic, juvenile, and adult mice by reverse transcription (RT)-PCR and in situ hybridization. In early brain development (embryonic day 12.5), AhR transcript was detected in the innermost cortical layer. The mRNA was also expressed in the hippocampus, cerebral cortex, cerebellum, olfactory bulb, and rostral migratory stream on embryonic day 18.5, postnatal days 3, 7, and 14, and in 12-week-old (adult) mice. Hippocampal expression was abundant in the CA1 and CA3 pyramidal and dentate gyrus granule cell layers, where expression level of AhR mRNA in 12-week old is higher than that in 7-day old. These results reveal temporal and spatial patterns of AhR mRNA expression in the mouse brain, providing the information that may contribute to the elucidation of the physiologic and toxicologic significance of AhR in the developing brain.

Keywords: aryl hydrocarbon receptor, cerebellum, cerebral cortex, hippocampus, in situ hybridization, mouse, olfactory bulb, rostral migratory stream

\section{INTRODUCTION}

The aryl hydrocarbon receptor (AhR) is a ligand-activated transcription factor belonging to the basic helix-loop-helix (bHLH)-Per-Arnt-Sim (PAS) family that is expressed in various organs. Its activation induces downstream pathways via expression of AhR-target genes such as cytochrome P450 (Cyp)1a1 and Cyp1b1 (Furness and Whelan, 2009). The gene encoding AhR is evolutionarily conserved from Caenorhabditis elegans to mammals (Hahn, 2002), and is thought to play essential roles in developmental and physiological processes. The function of AhR in the developing nervous 
system has been investigated by loss- and gain-of-function experiments. C. elegans ahr-1 was shown to regulate neuronal subtype specification, cell migration, and axonal branching (Huang et al., 2004; Qin and Powell-Coffman, 2004), while the Drosophila homolog Spineless controls dendritic arborization in sensory neuron subtypes (Kim et al., 2006). AhR deficiency in cerebellar neuron precursors during development leads to impairment of neurogenesis in mice (Dever et al., 2016). These results suggest an important role of $A h R$ in nervous system development. In fact, bHLH transcription factors are known to regulate developmental processes of the mammalian brain: in the cerebral cortex, Hairy and enhancer of split (Hes) 1 and Hes5 inhibit neuronal differentiation to maintain the neural stem cell pool (Ishibashi et al., 1994; Ohtsuka et al., 2001), while $c$-Myc and $N$-Myc regulate cellular proliferation in the cerebral cortex and cerebellum (Wey and Knoepfler, 2010; Wey et al., 2010). In addition, Single-minded homolog (Sim)1 and Sim 2 have been implicated in neuronal subtype specification in the hypothalamus (Michaud et al., 1998; Goshu et al., 2004). Similarly, AhR may regulate developmental processes in various brain regions. Although a previous study (Petersen et al., 2000) reported the presence of AhR mRNA in various brain regions of adult rats, no report has been available in the embryonic and early postnatal stages of in situ the developing mammalian brain.

Dioxin is a ubiquitous environmental contaminant and a known exogenous AhR ligand that has carcinogenic effects as well as reproductive and immune toxicity (Mandal, 2005). The majority of these toxic effects are exerted via an AhRdependent mechanism, as revealed by studies using AhR-null mice (Fernandez-Salguero et al., 1995; Schmidt et al., 1996; Mimura et al., 1997). In addition, rodents born to dams exposed to dioxin exhibit cognitive and behavioral abnormalities, including loss of behavioral flexibility, paired associate learning and memory, anxiety, and social behavior (Schantz et al., 1996; Markowski et al., 2001; Hojo et al., 2002; Mitsui et al., 2006; Haijima et al., 2010; Endo et al., 2012; Kakeyama et al., 2014). We recently found that exposure to dioxin in utero or through lactation causes abnormalities in dendritic morphology and upregulates the expression of class 3 semaphorin genes in the developing mouse brain (Kimura et al., 2015, 2016). These results suggest that the dioxin-AhR complex disrupts critical processes during brain development that ensure higher brain function in adulthood. Therefore, it would be worth studying spacio-temporal expression of AhR in the developing brain for understanding not only its possible physiologic roles, but also the mechanism of developmental neurotoxicity of dioxin.

To address this issue, the present study was performed to examine AhR mRNA expression in the developing mouse brain using reverse transcription (RT)-PCR method and a novel in situ hybridization approach known as RNAscope (Wang et al., 2012). We selected the hippocampus, cerebral cortex, cerebellum, and olfactory bulb for analysis, since perinatal dioxin exposure was previously found to induce AhR target gene expression in these regions (Kimura et al., 2016). We show the histochemical localization of AhR mRNA in the various regions of mouse brains during embryonic, juvenile, and adult periods.

\section{MATERIALS AND METHODS}

\section{Reagents}

Reagents were of analytical grade and purchased from Wako Pure Chemicals (Osaka, Japan), unless otherwise stated.

\section{Animals}

Experimental protocols were approved by the Animal Care and Use Committee of the University of Tokyo. Pregnant female or 12-week-old male C57BL/6J mice were purchased from CLEA Japan (Tokyo, Japan) and housed in an animal facility at a temperature of $22^{\circ} \mathrm{C}-24^{\circ} \mathrm{C}$ and humidity of $40-60 \%$ on a $12: 12-\mathrm{h}$ light/dark cycle (lights on from 08:00 to 20:00). Laboratory rodent chow (Lab MR Stock; Nosan, Yokohama, Japan) and distilled water were provided ad libitum. Male offspring at embryonic days (EDs) 12.5 or 18.5 , or postnatal days (PNDs) 3, 7, or 14 were
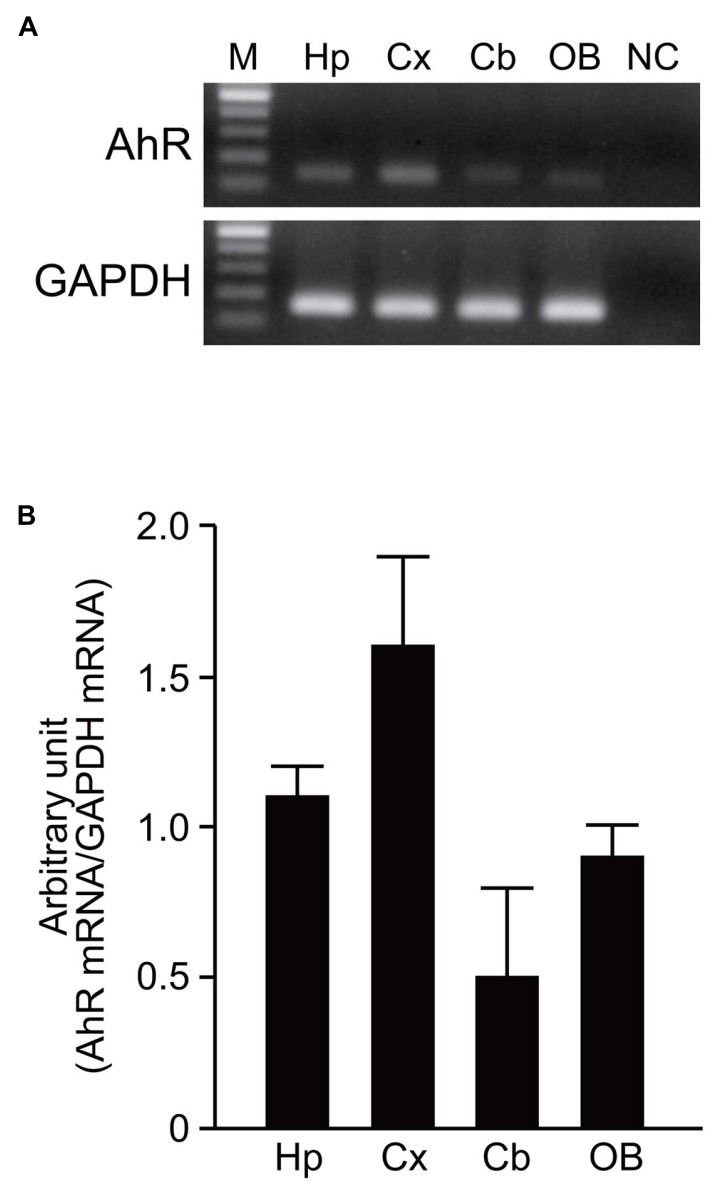

FIGURE 1 | AhR mRNA expression in the developing mouse brain. (A) AhR and GAPDH mRNA were amplified by RT-PCR in the hippocampus, cerebral cortex, cerebellum, and olfactory bulb on PND 7.

(B) Semi-quantitative analysis showed expression levels of AhR mRNA in four brain regions. The value was normalized by GAPDH mRNA expression. M, 100 bp marker; Hp, hippocampus; Cx, cerebral cortex; Cb, cerebellum; OB, olfactory bulb; NC, negative control. The values are shown as mean \pm SEM for three mice/brain region. 
selected for in situ hybridization analysis $(n=3$ mice at each stage of growth).

\section{Genotyping PCR}

To examine the sex of mouse embryos, genomic DNA was extracted from tail tips by lysing in $50 \mathrm{mM} \mathrm{NaOH}$ at $95^{\circ} \mathrm{C}$ for $2 \mathrm{~h}$. The lysate was mixed with $1 \mathrm{M}$ Tris- $\mathrm{HCl}(\mathrm{pH} 8.0)$ for neutralization, and centrifuged at $12,000 \mathrm{rpm}$ at room temperature for $10 \mathrm{~min}$. The genomic DNA in the supernatant was used as the template for PCR using a Takara Ex Taq PCR kit (Takara Bio, Kusatsu, Japan) on a Veriti thermal cycler (Applied Biosystems, Foster City, CA, USA). The amplification conditions were as follows: $95^{\circ} \mathrm{C}$ for $1 \mathrm{~min}$; and 40 cycles of $95^{\circ} \mathrm{C}$ for $15 \mathrm{~s}, 60^{\circ} \mathrm{C}$ for $30 \mathrm{~s}$, and $72^{\circ} \mathrm{C}$ for $30 \mathrm{~s}$. The PCR primers for amplifying the murine Sex-determining region $\mathrm{Y}$ (Sry) gene were $5^{\prime}$-gtggtgagaggcacaagttggc- $3^{\prime}$ and $5^{\prime}$-ctgtgtaggatcttcaatctct$3^{\prime}$. The $20-\mu 1$ reaction contained $250 \mathrm{nM}$ each primer, $1 \times \mathrm{Ex}$ Taq reaction buffer, $200 \mu \mathrm{M}$ each deoxynucleoside triphosphate (dNTP mixture), and $0.5 \mathrm{U}$ of Ex Taq DNA polymerase. PCR products were separated by electrophoresis on agarose gels that were stained with ethidium bromide. Genomic DNA from male embryos showed PCR products of the expected size (140 bp).

\section{RT-PCR}

Male offspring were sacrificed by decapitation on PND 7, and brain regions, including the hippocampus, cerebral cortex, cerebellum, and olfactory bulb, were quickly separated, and stored at $-80^{\circ} \mathrm{C}$ until analysis by RT-PCR. The total RNA was isolated from the each brain region using an RNeasy Mini Kit (Qiagen, Tokyo, Japan). The cDNA for a given mRNA was synthesized using oligo-dT and random hexamers with a Primescript RT reagent kit (Takara Bio). Expression of AhR and GAPDH mRNA were determined using Veriti thermal cycler (Applied Biosystems) with KOD Plus kit (Toyobo, Osaka, Japan). The amplification conditions were as follows: $95^{\circ} \mathrm{C}$ for $1 \mathrm{~min}$; and 30 cycles of $95^{\circ} \mathrm{C}$ for $15 \mathrm{~s}$, $55^{\circ} \mathrm{C}$ for $15 \mathrm{~s}$, and $68^{\circ} \mathrm{C}$ for $15 \mathrm{~s}$. The PCR primers for amplifying the murine AhR and GAPDH mRNA were $5^{\prime}$ tgtagagcacaaatcagaga- $3^{\prime} / 5^{\prime}$-gatagtggaggaagcatag- $3^{\prime}$, and $5^{\prime}$-ac ccagaagactgtggatgg- $3^{\prime} / 5^{\prime}$-cacattgggggtaggaacac- $3^{\prime}$, respectively. The $25-\mu$ l reaction solution contained $250 \mathrm{nM}$ each primer, $1 \times$ KOD Plus buffer, $200 \mu \mathrm{M}$ dNTP mixture, $1 \mathrm{mM} \mathrm{MgSO}_{4}$, and $0.5 \mathrm{U}$ of KOD Plus DNA polymerase. PCR products were separated by electrophoresis on agarose gels that were stained with Midori Green Advance (Nippon Gene, Tokyo, Japan). PCR products of AhR and GAPDH mRNA were expected to have 123 and $171 \mathrm{bp}$ in size, respectively.

\section{Tissue Preparation}

Whole ED 12.5 embryos and ED 18.5 brains were fixed overnight with $4 \%$ paraformaldehyde (PFA) in $0.1 \mathrm{M}$ phosphate-buffered saline (PBS, $\mathrm{pH} 7.4$ ). Male mice that were 3, 7, or 14 days or 12 weeks old, were anesthetized with sodium pentobarbital and perfused transcardially with 4\% PFA in 0.1 M PBS, and the brains were harvested and post-fixed overnight with 4\% PFA. Whole embryos or brains were dehydrated through a graded ethanol series and xylene and embedded in paraffin. Sagittal sections were cut at a thickness of $5 \mu \mathrm{m}$ using a sliding microtome (LS-113; Yamato Kohki, Saitama, Japan).

\section{In situ Hybridization}

In situ hybridization was performed using the RNAscope 2.0 HD Reagent kit (Brown) (Advanced Cell Diagnostics, Hayward, CA, USA) according to the manufacturer's instructions. Mouse AhR mRNA RNAscope probes were custom-made by Advanced Cell Diagnostics and targeted bases 867-1836 of mouse AhR mRNA (NCBI reference sequence: NM_013464.4). Probe sets specific for the housekeeping gene peptidylprolyl isomerase B (Ppib) from mouse and the dapB gene from Bacillus subtilis were used as positive and negative controls, respectively. After deparaffinization and dehydration, formalin-fixed sections were pretreated with protease and then subjected to in situ hybridization. Briefly, sections were hybridized with the probe solution, followed by amplification and probe detection using staining solutions. The sections were then stained with Gill's hematoxylin to visualize individual cells in each brain region. Slides were covered with Marinol (Muto Chemicals, Tokyo, Japan) and a plastic coverslip before viewing with a Leica DM6000 B microscope (Leica Microsystems, Tokyo, Japan). Bright-field images were captured using a Leica DM6000 B microscope with specific objective lenses (HCX PL APO, $40 \times$, $\mathrm{NA}=0.75$; Leica Microsystems).

\section{Punctate Signal Density Analysis}

The number of brown punctate signals of AhR mRNA were counted in the pyramidal cell layer, stratum orience (SO), and stratum radiatum $(\mathrm{SR})$ in the CA1 and CA3, and the granule

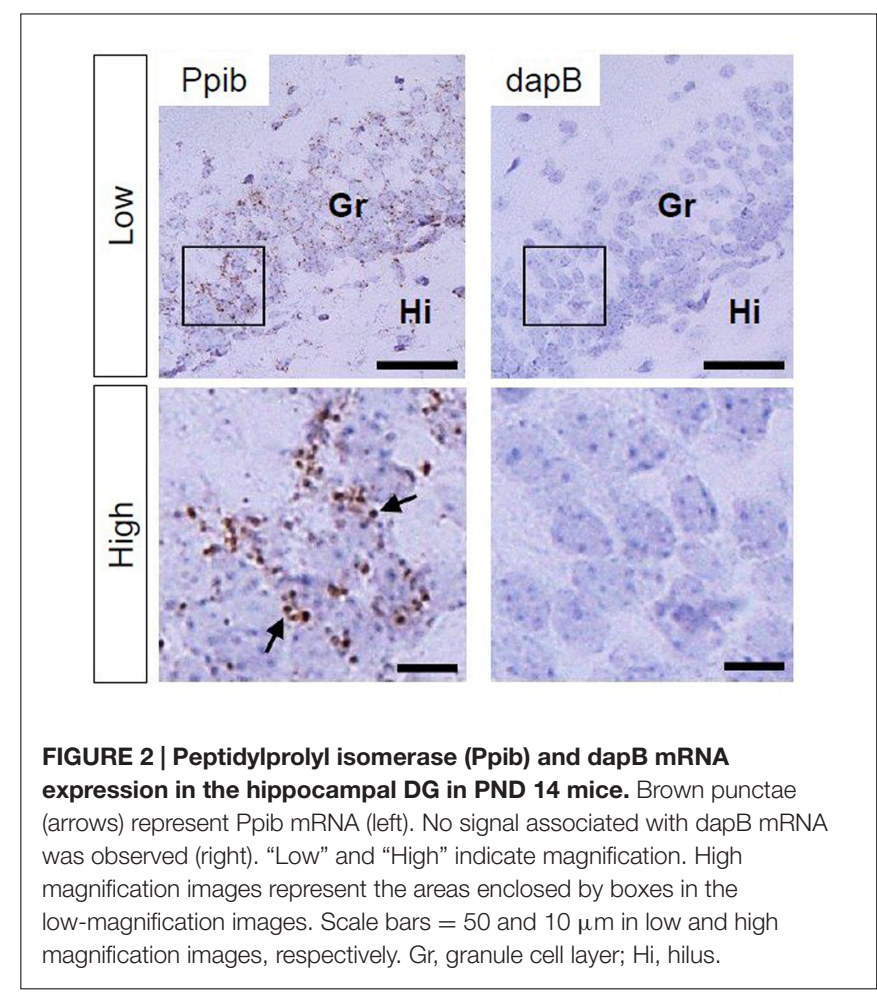



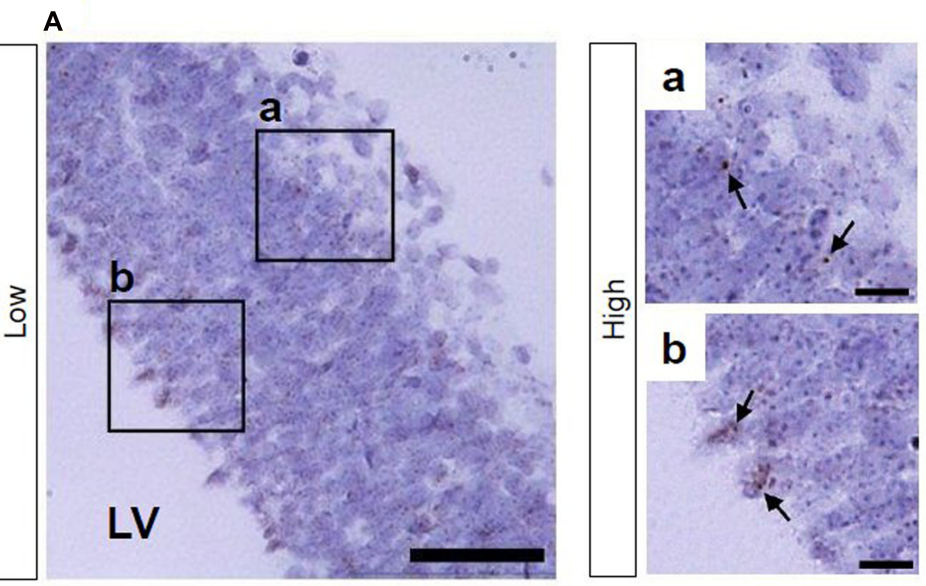

B

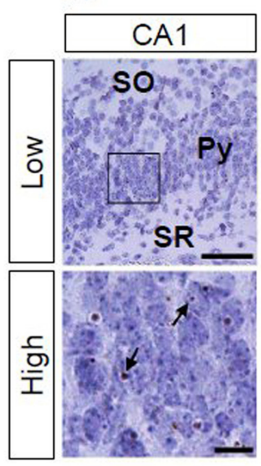

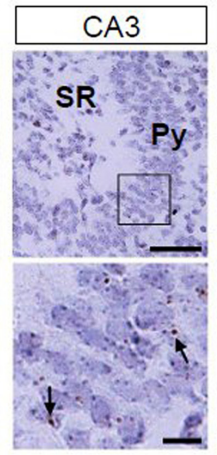
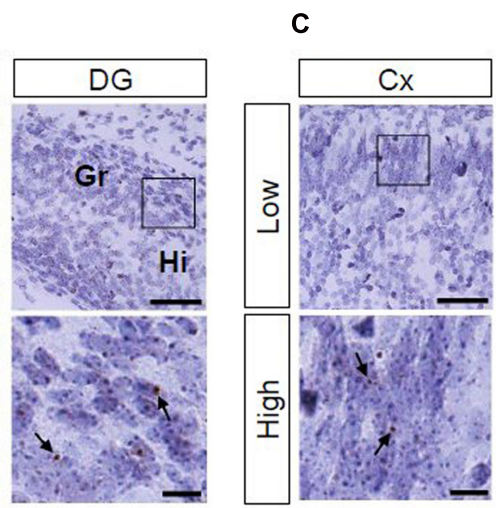

FIGURE 3 | AhR mRNA expression in the telencephalon of mice on ED 12.5 and ED 18.5. Brown punctae (arrows) represent AhR transcript in the cerebral cortex (A) on ED 12.5, and in the hippocampus (B) and cerebral cortex (C) on ED 18.5. "Low" and "High" indicate magnification. High magnification images represent the areas enclosed by boxes in the low-magnification images. Scale bars $=50$ and $10 \mu \mathrm{m}$ in low and high magnification images, respectively. Gr, granule cell layer; Hi, hilus; LV, lateral ventricle; Py, pyramidal cell layer; SO, stratum oriens; SR, stratum radiatum.

cell layer and hilus in the DG of the hippocampus from 7-dayold and 12-week-old mice. Punctate signal density was calculated by dividing the punctate signal number by area of each brain subregion.

\section{Statistical Analysis}

Expression level of AhR mRNA by RT-PCR was analyzed using the one-way analysis of various (ANOVA). Punctate density of AhR mRNA signals was analyzed using the two-way repeated measures ANOVA, followed by Tukey-Kramer test or Student's $t$-test. $P$-values $<0.05$ were considered statistically significant.

\section{RESULTS}

\section{RT-PCR Analysis of AhR mRNA Expression in the Developing Mouse \\ Brain}

AhR mRNA was detected in the hippocampus, cerebral cortex, cerebellum, and olfactory bulb of 7-day-old mice by RT-PCR analysis (Figure 1A). However, no significant difference in expression levels of AhR mRNA was observed in the four brain regions by semi-quantitative analysis (one-way ANOVA, $p=0.069$; Figure 1B).

\section{Histological Analysis of AhR mRNA Expression in the Embryonic Mouse Brain}

Using Ppib mRNA and dapB mRNA as positive and negative controls, respectively, for in situ hybridization by the RNAscope, we confirmed that the former showed brown punctate, but that the latter did not show any signals under the present experimental conditions (Figure 2). We evaluated AhR mRNA levels in the brain on ED 12.5 and ED 18.5. AhR transcript was detected in the cerebral cortex on ED 12.5 (Figure 3A), with strong signals in the innermost cortical layer. On ED 18.5, signals were observed in the hippocampus and cerebral cortex (Figures 3B,C). In the hippocampus, AhR mRNA signals were detected in the pyramidal cell layer of the CA1 and CA3, and granule cell layer of the DG regions (Figure 3B). 

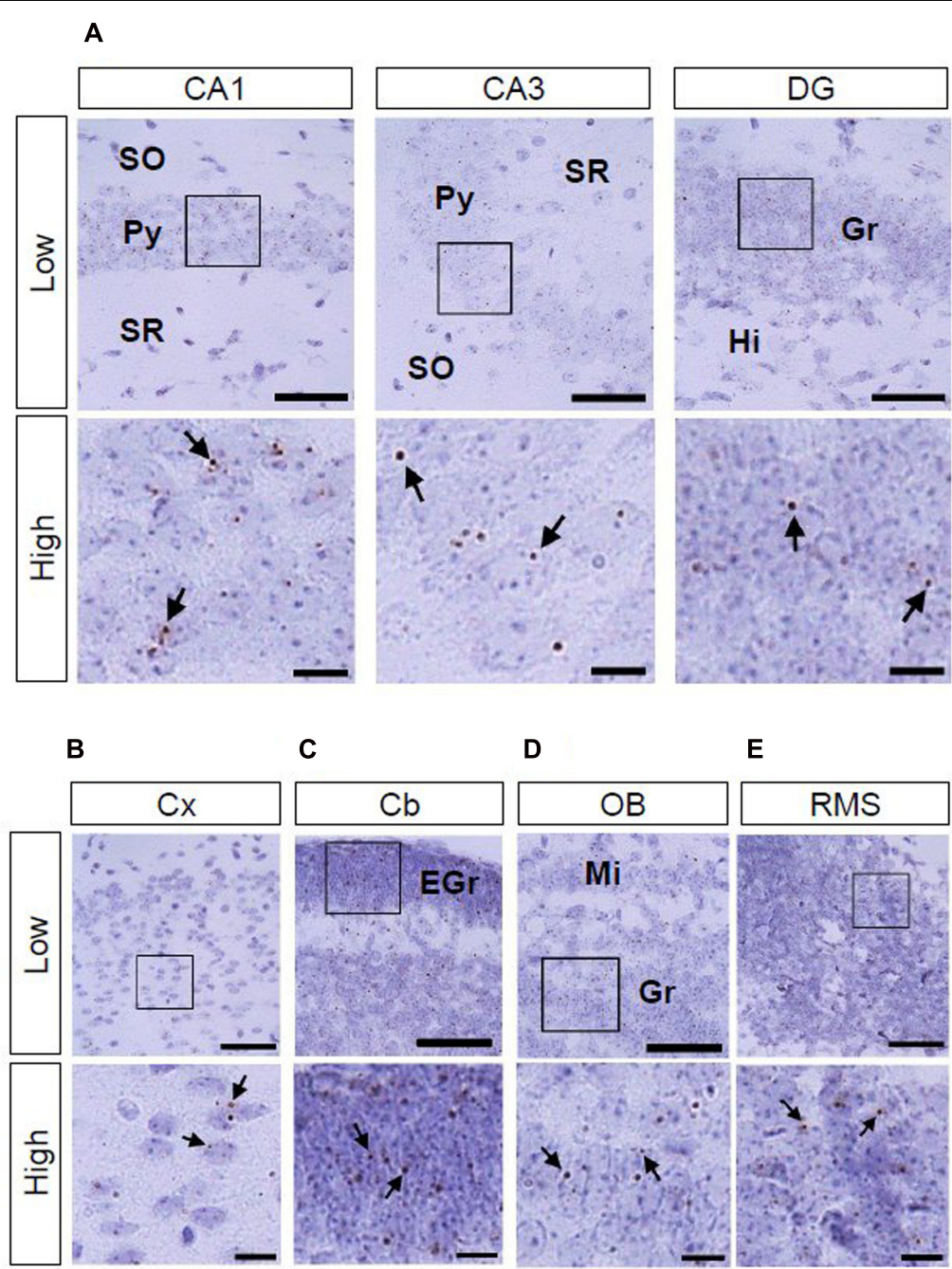

C

D

E
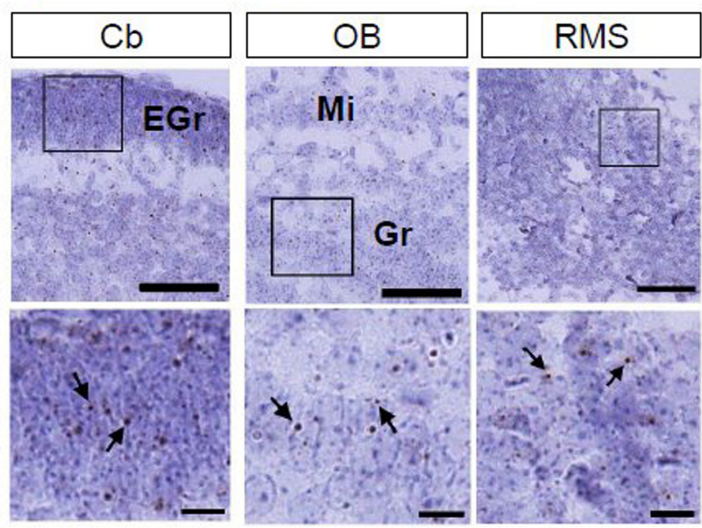

FIGURE 4 | AhR mRNA expression in various regions of mice on PND 7. Brown punctae (arrows) represent AhR transcript in the hippocampus (A), cerebral cortex (B), cerebellum (C), olfactory bulb (D), and RMS (E). "Low" and "High" indicate magnification. High magnification images represent the areas enclosed by boxes in the low-magnification images. Scale bars $=50$ and $10 \mu \mathrm{m}$ in low and high magnification images. EGr, external granule cell layer; Gr, granule cell layer; Hi, hilus; Mi, mitral cell layer; Py, pyramidal cell layer; SO, stratum oriens; SR, stratum radiatum.

\section{Histological Analysis of AhR mRNA Expression in the Juvenile Mouse Brain}

We also investigated AhR mRNA expression in the mouse brain on PNDs 3, 7, and 14. The transcript was observed in the CA1 and CA3 pyramidal cell layers and DG granule cell layer of the hippocampus (Figure 4A; Supplementary Figures S1A and S2A) as well as in the cerebral cortex (Figure 4B; Supplementary Figures S1B and S2B) at all three time points. In the cerebellum, AhR mRNA signals were present in the external granule cell layer on PNDs 3 (Supplementary Figure S1C) and 7 (Figure 4C) and in the granule cell layer on PND 14 (Supplementary Figure S2C). AhR mRNA signals were also detected in the granule cell layer of the olfactory bulb (Figure 4D; Supplementary Figures S1D and S2D) and the rostral migratory stream (RMS) on PNDs 3, 7, and 14 (Figure 4E; Supplementary Figures S1E and S2E).

\section{Histological Analysis of AhR mRNA Expression in the Adult Mouse Brain}

As to AhR mRNA expression in the brain of adult (12-week-old) mice, signals were observed in the hippocampal CA1 and CA3 pyramidal and DG granule cell layers, cerebral cortex, cerebellar and olfactory bulb granule cell layers, and RMS (Figures 5A-E).

\section{Quantitative Analysis of AhR mRNA Expression in the Developing and Adult Hippocampus}

We compared the density of punctate signals of AhR mRNA between subregions of the hippocampus and between ages (7-day old vs. 12-week old). Two-way repeated measures ANOVA indicated significant differences in the number of AhR mRNA punctate signals by subregion and by age, and a 

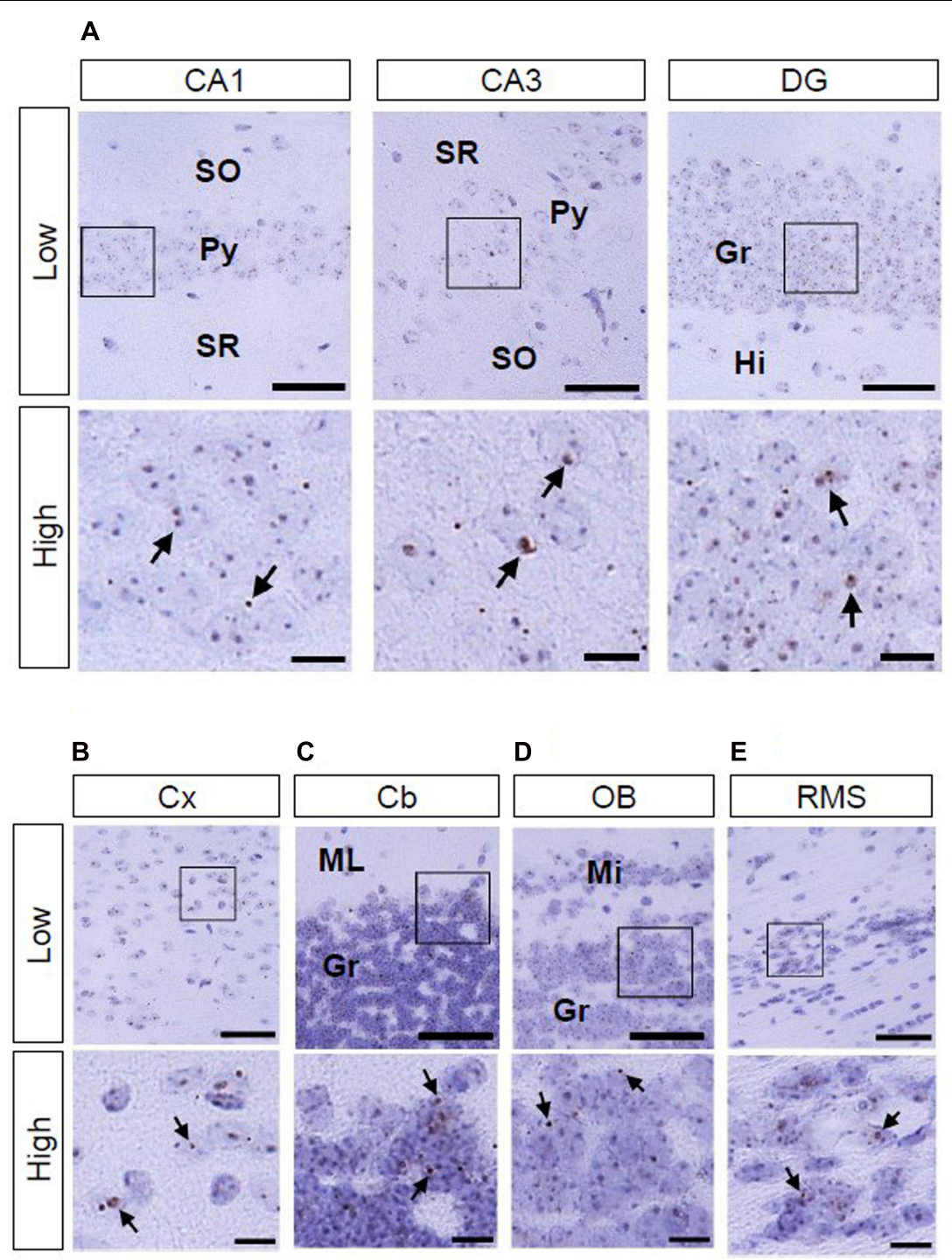

C

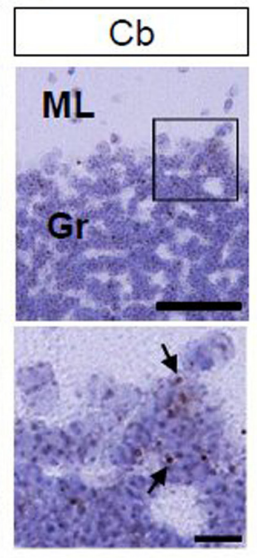

D

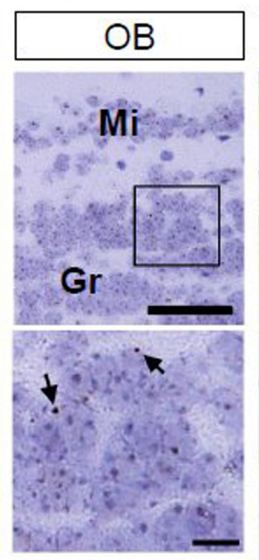

E

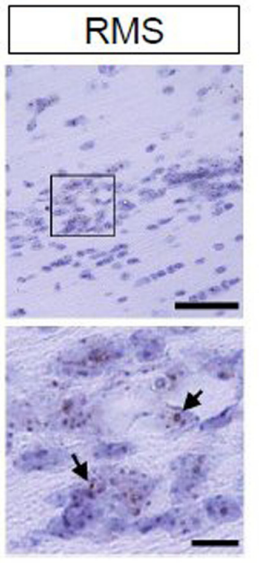

FIGURE 5 | AhR mRNA expression in various regions of mice in 12-week old. Brown punctae (arrows) represent AhR transcript in the hippocampus (A), cerebral cortex (B), cerebellum (C), olfactory bulb (D), and RMS (E). "Low" and "High" indicate magnification. High magnification images represent the area enclosed by boxes in the low-magnification images. Scale bars = 50 and $10 \mu \mathrm{m}$ in low and high magnification images. Gr, granule cell layer; Hi, hilus; Mi, mitral cell layer; ML, molecular layer; Py, pyramidal cell layer; SO, stratum oriens; SR, stratum radiatum.

significant interaction between these two factors in the CA1 $\left(p=6.33 \times 10^{-10}, 5.05 \times 10^{-5}\right.$, and $8.70 \times 10^{-6}$, respectively), CA3 $\left(p=2.04 \times 10^{-5}, 1.25 \times 10^{-3}\right.$, and $1.56 \times 10^{-2}$, respectively), and DG $\left(p=5.89 \times 10^{-6}, 6.67 \times 10^{-5}\right.$, and $9.24 \times 10^{-5}$, respectively; Figure 6). In the hippocampal CA1 regions, the punctate signal density in the pyramidal cell layer was significantly higher than that in the SO and SR in 7-day-old mice $(p<0.01$ and 0.01 , respectively) and adult mice $(p<0.01$ and 0.01 , respectively). The signal density in the CA3 pyramidal cell layer was significantly higher than that in the SO and SR in adult mice ( $p<0.01$ and 0.01 , respectively). Furthermore, the punctate signal density in the granule cell layer in DG was significantly higher than that in the hilus in 7-day-old mice and adult mice $(p<0.01$ and 0.001 , respectively). As to age, the punctate signal density in the CA1 and CA3 pyramidal and DG granule cell layers was significantly higher in the 12 -week-old mice than that in the 7-day-old mice $(p<0.01,0.01$, and 0.01 , respectively; Figure 6).

\section{DISCUSSION}

The present study using in situ hybridization demonstrated for the first time that AhR mRNA is expressed during embryonic development as well as postnatally in specific regions of the mouse brain. In development of the nervous system, an essential role of AhR has been demonstrated in a wide spectrum of animals, ranging from C. elegans to mouse. In brief, AhR 

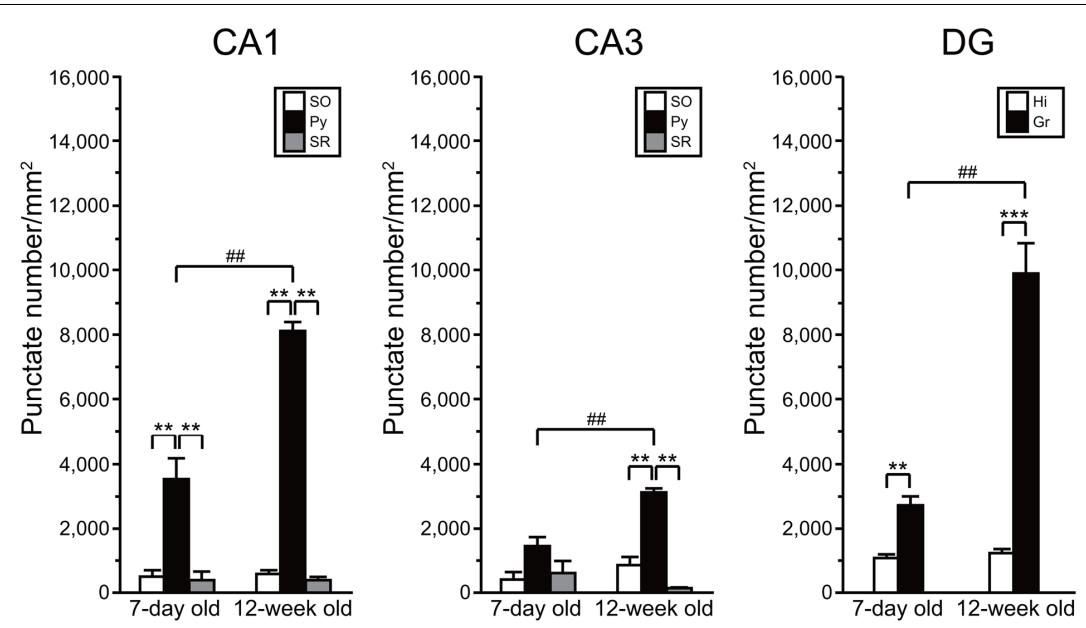

FIGURE 6 | Quantitative analysis of density of AhR mRNA signals in the hippocampal subregions in 7-day and 12-week old. Punctate density of AhR mRNA signals in the CA1, CA3, and DG in the hippocampus. Signal density in the CA1 and CA3 pyramidal cell layer (Py) and DG granule cell layer (Gr) was dramatically higher than that in the stratum oriens (SO) and stratum radiatum (SR) of CA1 and CA3, and hilus (Hi) of DG in 7-day-and 12-week-old mice. Signal density in the Py and Gr in 12-week-old mice was significantly increased when compared with that in the 7-day-old mice. ${ }^{* *}$ and ${ }^{* * *}$ indicate significant difference between the subregions $(p<0.01$ and 0.001 , respectively). \#\# indicates significant difference between ages $(p<0.01)$. The values are shown as mean \pm SEM for three mice/age.

regulates neuronal subtype specification, cellular migration, axonal branching and dendritic arborization in C. elegans and Drosophila (Huang et al., 2004; Qin and Powell-Coffman, 2004; Kim et al., 2006). In mice, neuronal progenitors lacking AhR show an impairment of neurogenesis in the developing cerebellum (Dever et al., 2016). In the present study, AhR mRNA was detected in the developing brain regions, including the hippocampus, cerebral cortex, cerebellum, and olfactory bulb (Figure 1). Hence, it is reasonable to consider that AhR has developmental and physiological roles in the mammalian brain.

In the present study, AhR mRNA was detected in the cerebral cortex on ED 12.5 (Figure 3A); importantly, the signal was strongest in the innermost cortical layer that is known to harbor neural stem cells in a previous study (Noctor et al., 2001). Thus, AhR may function in a manner similar to Hes1 and Hes5, which suppress differentiation of neural precursor cells (Ishibashi et al., 1994; Ohtsuka et al., 2001), and thereby control the timing and extent of neurogenesis in the cortex. AhR mRNA was expressed in the hippocampus, cerebral cortex, cerebellum, olfactory bulb, and RMS on PNDs 3 (Supplementary Figure S1), 7 (Figure 4), and 14 (Supplementary Figure S2). In the postnatal brain, dendritic and axonal elongation is essential for neural circuit formation, which is regulated by class 3 semaphorin genes (Polleux et al., 1998, 2000; Falk et al., 2005; Taniguchi et al., 2005; Takeuchi et al., 2010) as well as brain-derived neurotrophic factor (BDNF) (McAllister et al., 1995; Niblock et al., 2000). Glutamate and GABA receptor signaling also promotes dendritic arborization and synapse formation (Cline, 2001; Sernagor et al., 2010). Altered expression of genes by 2,3,7,8-teterachlorodibenzo- $p$-dioxin (TCDD), a most effective AhR agonist, has been reported. Class 3 semaphorin genes were induced by TCDD in the brain of red sea bream (Pagrus major) embryos and that of juvenile mice (Iida et al., 2013; Kimura et al., 2016). Gene expression of NMDA receptor subunit NR2A was enhanced, but NR2B was suppressed on PND 49 by in utero and lactational exposure to TCDD (Kakeyama et al., 2001). AhR knockdown reduced NMDA receptor subunit expression, attenuated NMDA receptor-mediated excitatory post-synaptic currents, and enhanced NMDA-induced BDNF expression (Lin et al., 2009). In addition, postnatal TCDD exposure reduces expression of GABA receptor subunit in the cerebellum (Collins et al., 2008). Expression of genes, such as neural cell adhesion molecule 1 and synaptophysin, which are involved in neural circuit formation in the embryonic telencephalon, was suppressed by TCDD exposure (Gohlke et al., 2009). Thus, AhR may participate in neural circuit formation by regulating gene expression.

In situ AhR mRNA expression has been reported in various regions of adult Sprague-Dawley rat brain, including the cerebral cortex, hippocampus, cerebellum, and olfactory bulb (Petersen et al., 2000). The transcript was also detected in neural stem cells in the subgranular zone of the hippocampal DG in adult C57BL/6 mice (Latchney et al., 2013). We observed AhR mRNA signals in the cerebral cortex; hippocampal CA1, CA3, and DG regions; cerebellum; and olfactory bulb in adult mice (Figures 5A-D), which is consistent with observations in adult rats (Petersen et al., 2000). AhR has been implicated in adult neurogenesis in the DG (Latchney et al., 2013). Besides, adult neurogenesis is observed in the granule neurons of the olfactory bulb in adulthood (Zhao et al., 2008). Neuronal precursors from the subventricular zone of the lateral ventricle migrate to the olfactory bulb via the RMS throughout adulthood. Our observation that AhR mRNA was expressed in the granule cell layer of the olfactory bulb and was present in the RMS in adult mice (Figures 5D,E) implies that AhR regulates adult neurogenesis not only in the hippocampus but also in the olfactory bulb. In the hippocampus, AhR transcript levels were elevated in the CA1 and CA3 pyramidal and DG 
granule cell layers (Figure 6) that are known to be rich in the number of neurons. In the CA1 and CA3 pyramidal and DG granule cell layers, expression levels of AhR mRNA in adult mice were significantly increased when compared with that in the developmental stage (Figure 6). AhR-null mice showed impairment of fear memory in adulthood (Latchney et al., 2013); thus, these results suggest that AhR expressed in neurons plays important roles not only in developmental processes, but also in higher brain function.

AhR mRNA expression was hardly observed in the fetal, postnatal, and adult periods of mice in the Allen Brain Atlas (ABA) (Lein et al., 2007; Henry and Hohmann, 2012). On the other hand, our present study successfully detected the AhR mRNA expression in multiple regions of the brain. The inconsistent results between our study and the ABA may be due to the following reasons. First, the detection sensitivity of the RNAscope may be much higher than the digoxygenin-labeled antisense probe used in the ABA. Second, the target regions of probes used are different between two studies. The present study and ABA used base sequences of 867-1836 and 3596-4276, respectively.

Perinatal dioxin exposure perturbs dendritic morphology of hippocampal CA1 pyramidal neurons (Kimura et al., 2015), cortical layer formation (Mitsuhashi et al., 2010), and neurogenesis in cerebellar granule cells (Collins et al., 2008). Although the molecular mechanisms underlying the developmental neurotoxicity of dioxin remain unclear, our observations suggest that dioxin causes hyperactivation of AhR and downstream signaling pathways in AhR-expressing cells in the brain, thereby dysregulating developmental processes required for higher brain function in adulthood. Adverse circumstances during gestational period have been reported to be a cause of adult onset diseases, and the paradigm named 'developmental origins of health and disease' has been widely accepted (Wadhwa et al., 2009). The present findings suggest that this theory can be applied to environmental

\section{REFERENCES}

Cline, H. T. (2001). Dendritic arbor development and synaptogenesis. Curr. Opin. Neurobiol. 11, 118-126. doi: 10.1016/S0959-4388(00)00182-3

Collins, L. L., Williamson, M. A., Thompson, B. D., Dever, D. P., Gasiewicz, T. A., and Opanashuk, L. A. (2008). 2,3,7,8-Tetracholorodibenzo-pdioxin exposure disrupts granule neuron precursor maturation in the developing mouse cerebellum. Toxicol. Sci. 103, 125-136. doi: 10.1093/toxsci/ $\mathrm{kfn} 017$

Dever, D. P., Adham, Z. O., Thompson, B., Genestine, M., Cherry, J., Olschowka, J. A., et al. (2016). Aryl hydrocarbon receptor deletion in cerebellar granule neuron precursors impairs neurogenesis. Dev. Neurobiol. 76, 533-550. doi: 10.1002/dneu. 22330

Endo, T., Kakeyama, M., Uemura, Y., Haijima, A., Okuno, H., Bito, H., et al. (2012). Executive function deficits and social-behavioral abnormality in mice exposed to a low dose of dioxin in utero and via lactation. PLoS ONE 7:e50741. doi: 10.1371/journal.pone.0050741

Falk, J., Bechara, A., Fiore, R., Nawabi, H., Zhou, H., Hoyo-Becerra, C., et al. (2005). Dual functional activity of semaphorin $3 \mathrm{~B}$ is required for positioning the anterior commissure. Neuron 48, 63-75. doi: 10.1016/j.neuron.2005. 10.024 chemical exposure during the developmental period of life.

\section{AUTHOR CONTRIBUTIONS}

EK and CT conceived and designed this study; EK performed experiments and analyzed data; EK and CT wrote the manuscript.

\section{ACKNOWLEDGMENTS}

This work was supported in part by grant from the JSPS Kakenhi (JP24221003 to CT). We would like to thank Editage for English language editing. We thank New Histo. Science Laboratory Co. for technical support.

\section{SUPPLEMENTARY MATERIAL}

The Supplementary Material for this article can be found online at: http://journal.frontiersin.org/article/10.3389/fnana. 2017.00004/full\#supplementary-material

FIGURE S1 | AhR mRNA expression in various regions of mice on PND 3. Brown punctae (arrows) represent AhR transcript in the hippocampus (A), cerebral cortex (B), cerebellum (C), olfactory bulb (D), and RMS (E). "Low" and "High" indicate magnification. High magnification images represent the areas enclosed by boxes in the low-magnification images. Scale bars $=50$ and $10 \mu \mathrm{m}$ in low and high magnification images. EGr, external granule cell layer; Gr, granule cell layer; $\mathrm{Hi}$, hilus; Mi, mitral cell layer; Py, pyramidal cell layer; SO, stratum oriens; SR, stratum radiatum.

FIGURE S2 | AhR mRNA expression in various regions of mice on PND 14. Brown punctae (arrows) represent AhR transcript in the hippocampus (A), cerebral cortex (B), cerebellum (C), olfactory bulb (D), and RMS (E). "Low" and "High" indicate magnification. High magnification images represent the areas enclosed by boxes in the low-magnification images. Scale bars $=50$ and $10 \mu \mathrm{m}$ in low and high magnification images. Gr, granule cell layer; Hi, hilus; Mi, mitral cell layer; ML, molecular layer; Py, pyramidal cell layer; SO, stratum oriens; SR, stratum radiatum.
Fernandez-Salguero, P., Pineau, T., Hilbert, D. M., Mcphail, T., Lee, S. S., Kimura, S., et al. (1995). Immune system impairment and hepatic fibrosis in mice lacking the dioxin-binding Ah receptor. Science 268, 722-726. doi: 10. $1126 /$ science. 7732381

Furness, S. G., and Whelan, F. (2009). The pleiotropy of dioxin toxicity-xenobiotic misappropriation of the aryl hydrocarbon receptor's alternative physiological roles. Pharmacol. Ther. 124, 336-353. doi: 10.1016/j.pharmthera.2009. 09.004

Gohlke, J. M., Stockton, P. S., Sieber, S., Foley, J., and Portier, C. J. (2009). AhRmediated gene expression in the developing mouse telencephalon. Reprod. Toxicol. 28, 321-328. doi: 10.1016/j.reprotox.2009.05.067

Goshu, E., Jin, H., Lovejoy, J., Marion, J. F., Michaud, J. L., and Fan, C. M. (2004). $\operatorname{Sim} 2$ contributes to neuroendocrine hormone gene expression in the anterior hypothalamus. Mol. Endocrinol. 18, 1251-1262. doi: 10.1210/me.2003-0372

Hahn, M. E. (2002). Aryl hydrocarbon receptors: diversity and evolution. Chem. Biol. Interact. 141, 131-160. doi: 10.1016/S0009-2797(02)00070-4

Haijima, A., Endo, T., Zhang, Y., Miyazaki, W., Kakeyama, M., and Tohyama, C. (2010). In utero and lactational exposure to low doses of chlorinated and brominated dioxins induces deficits in the fear memory of male mice. Neurotoxicology 31, 385-390. doi: 10.1016/j.neuro.2010. 04.004 
Henry, A. M., and Hohmann, J. G. (2012). High-resolution gene expression atlases for adult and developing mouse brain and spinal cord. Mamm. Genome 23, 539-549. doi: 10.1007/s00335-012-9406-2

Hojo, R., Stern, S., Zareba, G., Markowski, V. P., Cox, C., Kost, J. T., et al. (2002). Sexually dimorphic behavioral responses to prenatal dioxin exposure. Environ. Health Perspect. 110, 247-254. doi: 10.1289/ehp.02110247

Huang, X., Powell-Coffman, J. A., and Jin, Y. (2004). The AHR-1 aryl hydrocarbon receptor and its co-factor the AHA-1 aryl hydrocarbon receptor nuclear translocator specify GABAergic neuron cell fate in C. elegans. Development 131, 819-828. doi: 10.1242/dev.00959

Iida, M., Kim, E. Y., Murakami, Y., Shima, Y., and Iwata, H. (2013). Toxic effects of 2,3,7,8-tetrachlorodibenzo-p-dioxin on the peripheral nervous system of developing red seabream (Pagrus major). Aquat. Toxicol. 12, 193-202. doi: 10.1016/j.aquatox.2012.12.009

Ishibashi, M., Moriyoshi, K., Sasai, Y., Shiota, K., Nakanishi, S., and Kageyama, R. (1994). Persistent expression of helix-loop-helix factor HES-1 prevents mammalian neural differentiation in the central nervous system. EMBO J. 13, 1799-1805.

Kakeyama, M., Endo, T., Zhang, Y., Miyazaki, W., and Tohyama, C. (2014). Disruption of paired-associate learning in rat offspring perinatally exposed to dioxins. Arch. Toxicol. 88, 789-798. doi: 10.1007/s00204-013-1161-y

Kakeyama, M., Sone, H., and Tohyama, C. (2001). Changes in expression of NMDA receptor subunit mRNA by perinatal exposure to dioxin. Neuroreport 12, 4009-4012. doi: 10.1097/00001756-200112210-00031

Kim, M. D., Jan, L. Y., and Jan, Y. N. (2006). The bHLH-PAS protein Spineless is necessary for the diversification of dendrite morphology of Drosophila dendritic arborization neurons. Genes Dev. 20, 2806-2819. doi: 10.1101/gad. 1459706

Kimura, E., Endo, T., Yoshioka, W., Ding, Y., Ujita, W., Kakeyama, M., et al. (2016). In utero and lactational dioxin exposure induces Sema3b and Sema3g gene expression in the developing mouse brain. Biochem. Biophys. Res. Commun. 476, 108-113. doi: 10.1016/j.bbrc.2016.05.048

Kimura, E., Kubo, K., Matsuyoshi, C., Benner, S., Hosokawa, M., Endo, T., et al. (2015). Developmental origin of abnormal dendritic growth in the mouse brain induced by in utero disruption of aryl hydrocarbon receptor signaling. Neurotoxicol. Teratol. 52, 42-50. doi: 10.1016/j.ntt.2015.10.005

Latchney, S. E., Hein, A. M., O’banion, M. K., Dicicco-Bloom, E., and Opanashuk, L. A. (2013). Deletion or activation of the aryl hydrocarbon receptor alters adult hippocampal neurogenesis and contextual fear memory. J. Neurochem. 125, 430-445. doi: 10.1111/jnc. 12130

Lein, E. S., Hawrylycz, M. J., Ao, N., Ayres, M., Bensinger, A., Bernard, A., et al. (2007). Genome-wide atlas of gene expression in the adult mouse brain. Nature 445, 168-176. doi: 10.1038/nature05453

Lin, C. H., Chen, C. C., Chou, C. M., Wang, C. Y., Hung, C. C., Chen, J. Y., et al. (2009). Knockdown of the aryl hydrocarbon receptor attenuates excitotoxicity and enhances NMDA-induced BDNF expression in cortical neurons. J. Neurochem. 111, 777-789. doi: 10.1111/j.1471-4159.2009. 06364.x

Mandal, P. K. (2005). Dioxin: a review of its environmental effects and its aryl hydrocarbon receptor biology. J. Comp. Physiol. B 175, 221-230. doi: 10.1007/ s00360-005-0483-3

Markowski, V. P., Zareba, G., Stern, S., Cox, C., and Weiss, B. (2001). Altered operant responding for motor reinforcement and the determination of benchmark doses following perinatal exposure to low-level 2,3,7,8tetrachlorodibenzo-p-dioxin. Environ. Health Perspect. 109, 621-627. doi: 10. 1289/ehp.01109621

McAllister, A. K., Lo, D. C., and Katz, L. C. (1995). Neurotrophins regulate dendritic growth in developing visual cortex. Neuron 15, 791-803. doi: 10.1016/ 0896-6273(95)90171-X

Michaud, J. L., Rosenquist, T., May, N. R., and Fan, C. M. (1998). Development of neuroendocrine lineages requires the bHLH-PAS transcription factor SIM1. Genes Dev. 12, 3264-3275. doi: 10.1101/gad.12.20.3264

Mimura, J., Yamashita, K., Nakamura, K., Morita, M., Takagi, T. N., Nakao, K., et al. (1997). Loss of teratogenic response to 2,3,7,8-tetrachlorodibenzo-p-dioxin (TCDD) in mice lacking the Ah (dioxin) receptor. Genes Cells 2, 645-654. doi: 10.1046/j.1365-2443.1997.1490345.x

Mitsuhashi, T., Yonemoto, J., Sone, H., Kosuge, Y., Kosaki, K., and Takahashi, T. (2010). In utero exposure to dioxin causes neocortical dysgenesis through the actions of p27Kip1. Proc. Natl. Acad. Sci. U.S.A. 107, 16331-16335. doi: 10.1073/ pnas. 1002960107

Mitsui, T., Sugiyama, N., Maeda, S., Tohyama, C., and Arita, J. (2006). Perinatal exposure to 2,3,7,8-tetrachlorodibenzo-p-dioxin suppresses contextual fear conditioning-accompanied activation of cyclic AMP response element-binding protein in the hippocampal CA1 region of male rats. Neurosci. Lett. 398, 206-210. doi: 10.1016/j.neulet.2005.12.087

Niblock, M. M., Brunso-Bechtold, J. K., and Riddle, D. R. (2000). Insulin-like growth factor I stimulates dendritic growth in primary somatosensory cortex. J. Neurosci. 20, 4165-4176.

Noctor, S. C., Flint, A. C., Weissman, T. A., Dammerman, R. S., and Kriegstein, A. R. (2001). Neurons derived from radial glial cells establish radial units in neocortex. Nature 409, 714-720. doi: 10.1038/35055553

Ohtsuka, T., Sakamoto, M., Guillemot, F., and Kageyama, R. (2001). Roles of the basic helix-loop-helix genes Hes1 and Hes5 in expansion of neural stem cells of the developing brain. J. Biol. Chem. 276, 30467-30474. doi: 10.1074/jbc. M102420200

Petersen, S. L., Curran, M. A., Marconi, S. A., Carpenter, C. D., Lubbers, L. S., and Mcabee, M. D. (2000). Distribution of mRNAs encoding the arylhydrocarbon receptor, arylhydrocarbon receptor nuclear translocator, and arylhydrocarbon receptor nuclear translocator-2 in the rat brain and brainstem. J. Comp. Neurol. 427, 428-439. doi: 10.1002/1096-9861(20001120)427:3<428::AID-CNE9>3.0. $\mathrm{CO} ; 2-\mathrm{P}$

Polleux, F., Giger, R. J., Ginty, D. D., Kolodkin, A. L., and Ghosh, A. (1998). Patterning of cortical efferent projections by semaphorinneuropilin interactions. Science 282, 1904-1906. doi: 10.1126/science.282. 5395.1904

Polleux, F., Morrow, T., and Ghosh, A. (2000). Semaphorin 3A is a chemoattractant for cortical apical dendrites. Nature 404, 567-573. doi: 10.1038/ 35007001

Qin, H., and Powell-Coffman, J. A. (2004). The Caenorhabditis elegans aryl hydrocarbon receptor, AHR-1, regulates neuronal development. Dev. Biol. 270, 64-75.

Schantz, S. L., Seo, B. W., Moshtaghian, J., Peterson, R. E., and Moore, R. W. (1996). Effects of gestational and lactational exposure to TCDD or coplanar PCBs on spatial learning. Neurotoxicol. Teratol. 18, 305-313. doi: 10.1016/S08920362(96)90033-1

Schmidt, J. V., Su, G. H., Reddy, J. K., Simon, M. C., and Bradfield, C. A. (1996). Characterization of a murine Ahr null allele: involvement of the Ah receptor in hepatic growth and development. Proc. Natl. Acad. Sci. U.S.A. 93, 6731-6736. doi: $10.1073 /$ pnas.93.13.6731

Sernagor, E., Chabrol, F., Bony, G., and Cancedda, L. (2010). GABAergic control of neurite outgrowth and remodeling during development and adult neurogenesis: general rules and differences in diverse systems. Front. Cell Neurosci. 4:11. doi: $10.3389 /$ fncel.2010.00011

Takeuchi, H., Inokuchi, K., Aoki, M., Suto, F., Tsuboi, A., Matsuda, I., et al. (2010). Sequential arrival and graded secretion of Sema3F by olfactory neuron axons specify map topography at the bulb. Cell 141, 1056-1067. doi: 10.1016/j.cell. 2010.04 .041

Taniguchi, M., Masuda, T., Fukaya, M., Kataoka, H., Mishina, M., Yaginuma, H., et al. (2005). Identification and characterization of a novel member of murine semaphorin family. Genes Cells 10, 785-792. doi: 10.1111/j.1365-2443.2005. 00877.x

Wadhwa, P. D., Buss, C., Entringer, S., and Swanson, J. M. (2009). Developmental origins of health and disease: brief history of the approach and current focus on epigenetic mechanisms. Semin. Reprod. Med. 27, 358-368. doi: 10.1055/s-00291237424

Wang, F., Flanagan, J., Su, N., Wang, L. C., Bui, S., Nielson, A., et al. (2012). RNAscope: a novel in situ RNA analysis platform for formalin-fixed, paraffinembedded tissues. J. Mol. Diagn. 14, 22-29. doi: 10.1016/j.jmoldx.2011. 08.002

Wey, A., and Knoepfler, P. S. (2010). c-myc and N-myc promote active stem cell metabolism and cycling as architects of the developing brain. Oncotarget 1, 120-130. doi: 10.18632/oncotarget.116

Wey, A., Martinez Cerdeno, V., Pleasure, D., and Knoepfler, P. S. (2010). cand $\mathrm{N}$-myc regulate neural precursor cell fate, cell cycle, and metabolism to direct cerebellar development. Cerebellum 9, 537-547. doi: 10.1007/s12311-0100190-9 
Zhao, C., Deng, W., and Gage, F. H. (2008). Mechanisms and functional implications of adult neurogenesis. Cell 132, 645-660. doi: 10.1016/j.cell.2008. 01.033

Conflict of Interest Statement: The authors declare that the research was conducted in the absence of any commercial or financial relationships that could be construed as a potential conflict of interest.
Copyright (c) 2017 Kimura and Tohyama. This is an open-access article distributed under the terms of the Creative Commons Attribution License (CC BY). The use, distribution or reproduction in other forums is permitted, provided the original author(s) or licensor are credited and that the original publication in this journal is cited, in accordance with accepted academic practice. No use, distribution or reproduction is permitted which does not comply with these terms. 